\title{
ENVIRONMENTAL REGULATION, DIRECTED TECHNOLOGICAL CHANGE, AND ECONOMIC GROWTH: FROM THE PERSPECTIVE OF GREEN GROWTH
}

\author{
ZHOU, J. M. ${ }^{1,2}-$ ZHAO, Y. Z. ${ }^{2 *}-$ KUANG, H. B. ${ }^{2}$

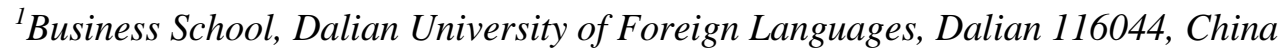 \\ ${ }^{2}$ Collaborative Innovation Center for Transport Studies, Dalian Maritime University \\ Dalian 116026, China \\ *Corresponding author \\ e-mail: zhaoyuzhe@126.com; phone: +86-18-698-606-670; fax: +86-411-8472-8856
}

(Received $3^{\text {rd }}$ Apr 2019; accepted $17^{\text {th }}$ May 2019)

\begin{abstract}
For the problem concerning how the implementation of environmental regulations should be performed, one must examine their impacts on the selection of directed technological innovations to achieve green growth. A nonlinear control model was created in which the constraint is to constantly improve the quality of the environment and ensure a consistent and balanced growth rate with the objective function being the goal of using green growth to maximize social welfare. Using optimal control theory and the maximum principle, we separately obtained the qualitative expression of capital allocation and optimal consumption growth. The model simulation results illustrate the following points: although brown capital is superior in production flexibility in the process of capital accumulation, green capital is still an important pillar of support for maintaining the economic growth of a society as a whole; although brown capital is able to bring about a greater consumption growth rate, the implementation of environmental regulations is sufficient to promote capital allocation to shift towards green technological innovation. In addition, greater emphasis in this aspect shall be more useful for the usage of green capital and play a more effective role in the use of green technological innovation to achieve green growth.

Keywords: environmental governance, capital allocation, green technological innovation, brown technological innovation, optimal control model, capital accumulation, environmental quality
\end{abstract}

\section{Introduction}

The key variables for explaining economic growth using traditional neoclassical economic growth theories are mainly capital, labor (including human resource capital), technology, and regulations. The standard for measuring economic growth is gross domestic product (GDP) and per capita income. However, amid the growth of contemporary society, GDP and per capita income are not the only yardsticks for reflecting social progress. Regardless of whether the ecosystem has a positive or negative impact, it has a direct impact on people's quality of life. Therefore, to reflect the goal of sustainable social growth, we must discard the original "GDP-oriented economic growth theory" and include resource usage and environmental impacts in mainstream economic growth theories to construct a "green growth theory", which we use as a new perspective of current mainstream economic research. With regard to green growth (OECD, 2011), technological innovation is the most important factor (Caselli, 2005) for maintaining economic growth. The implementation of some environmental regulations may affect the costs and earnings from technological innovation and change its direction of technological innovation. This effect may lead to "brown technological innovation that relies mainly on pollution-oriented inputs" and "green technological innovation (Demirel and Kesidou, 2011; Zhang and Zhu, 2012; Li et al., 2018) that 
attempts to reduce resource utilization and environmental impacts", both of which are problems related to direction-orientated technological innovation. Currently, research into these problems heavily focuses on the dominant factors (Gerlagh, 2011; Gans, 2011) that affect the selection of directed technological innovation. However, we need a further breakthrough to determine how the implementation of environmental regulations will affect the selection of directed technological innovations and what impact this implementation will have on the economic growth of society as a whole.

Currently, there are mainly two perspectives in relevant literature on the impact of the implementation of environmental regulations on technological innovation. The first viewpoint is the "Porter Hypothesis", which argues that the implementation of environmental policies can drive technological innovation and that these innovative technologies often originate from activities such as "learning by doing" and adapting to the local environment. Hart (2004) argues that if the next generation of products is cleaner than the previous generation of products, then the introduction of pollution taxes can reduce the inventory ratios of old products, which may in turn accelerate the elimination of obsolete production capacity and encourage the research and development of new technologies. Ghisetti and Pontoni (2015) prove that if companies or private departments are required to provide compensated protection of eco-service systems, then the implementation of environmental regulations can still improve technological standards. Jaffe et al. (2002), Hamamoto (2006), Zhang et al. (2011), Nick et al. (2012) and Rubashkina et al. (2015) support the "Porter Hypothesis" from the perspective of companies and society as a whole. These studies indicate that we not only view technological innovation from the internal perspective of companies. There is another perspective that opposes the "Porter Hypothesis". Stokey (1998) argues that when the implementation of environmental regulations requires a reduction in the mining of certain fossil fuels, this requirement will not only reduce the marginal output of capital but also reduce innovation in that particular field. "Learning by doing" is restricted, and the accumulation of knowledge capital is also reduced. In addition, the reduction of capital returns also further reduces the extent of technological inputs by companies. Arduini and Cesaroni (2001) use European chemical industrial data, Nakano (2003) uses data from the Japanese paper-making industry, and Barbera and McConnel (1990) use empirical study results of US industrial data to prove that the implementation of environmental regulations does not play a significant catalytic role in technological advancement and efficiency improvement.

The above-mentioned research debates the impact of the implementation of environmental regulations on technological innovation from two opposing perspectives. However, these existing studies have not taken into account the differentiation of directed technological innovation and dynamic changes in environmental regulatory strength. First, the crux of whether the implementation of environmental regulations can be a driver of green growth lies in the correct selection of environmental regulatory strength (Li and Tao, 2012). Only by selecting the environmental regulatory strength that corresponds with the level of economic growth will the long-term implementation of environmental regulations not obstruct the green growth of society as a whole. Zhang et al. (2011) construct a model to illustrate the impact of environmental regulatory strength on technological innovation and use empirical data to demonstrate the Ushaped relationship between environmental regulatory strength and technological innovation. Shen (2012) argues that the level of economic growth determines the impact of environmental regulations on technological innovation. In China, such regulations 
have a significant catalytic effect on the highly economically developed eastern regions of China but have a suppressive effect on the central and western regions of China. Second, not all technological innovations can be effective in protecting the environment while maintaining economic growth. The differentiation of directed technological innovation is one of the core contents regarding the study of green growth drivers. Targeting the impact of the implementation of environmental regulations, Smulders and Werf (2005) differentiate technological innovations into brown technological innovations and green technological innovations. Goulder (2004) and Smulders and Nooij (2003) argue that when it is relatively difficult for capital inputs to replace resource factor inputs, investments in green technology are necessary to maintain longterm economic growth. In their model analysis, during the implementation of environmental regulations, only green technological innovations are faster than brown technology innovations, and the negative impact of the reduction in resource utilization shall be effectively offset by green technological innovations. However, in the event of market failure, there is no guarantee that technological innovation can guarantee that the expected trajectory can be achieved even while underpinned by environmental regulations. Maria and Werf (2008) demonstrate that when intellectual property cannot be protected, green technological innovation drivers may be reduced, which may cause technological innovation to shift towards brown technology. The organic directionoriented technological innovation model constructed by Bondarev et al. (2014) further proves that with adequate guidance from environmental regulations, green technological innovation activities will be more active and boost the overall production rate and levels of economic growth.

After studying the above-mentioned literature concerning environmental regulatory strength and directed technological innovation to explore methods of how to achieve green growth, it can be observed that few academics are able to establish a quantitative model to explain these two important factors and the objective of green growth. Rauscher (2009) constructs an organic growth model based on environmental economics to quantitatively illustrate brown technological innovation investment and green technological innovation investment. Furthermore, Moser et al. (2013) use composite functions to produce a quantitative expression of green growth targets based on the model built by Rauscher (2009) and use a partial equilibrium model to analyze the directed effects of environmental regulations of different strengths on brown technological innovation and green technological innovation. The above-mentioned models are verifiable quantitative models concerning the strength of environmental regulations and directed technological innovations that verify the importance of technological innovations in realizing green growth, but they generally ignore the fact that technological innovation is a driving factor of green growth despite not being final objective. Green growth has a guiding and binding effect (Zhang and Zhu, 2012) on the direction of technological innovation. On the other hand, the utility functions concerning green growth in the model constructed by Moser et al. (2013). only takes into account a special situation in which the relative risk aversion coefficient is 1 but not general scenarios.

Therefore, the present research, which is based on the model constructed by Rauscher (2009) and Moser et al. (2013), also includes brown technological innovation and green technological innovation in the capital accumulation analytical framework. Figure 1 shows that there is an assumption that the effect of economies of scale is unchanged and that there is perfect competition in the market, taking into account 
pollution control efforts and environmental governance costs under different environmental regulatory strengths. This has led to the creation of a non-linear optimal control model in which the objective function is the green growth target of maximizing social welfare and the constraints are ensuring sustained growth with a balanced growth rate and sustained improvement in environmental quality.

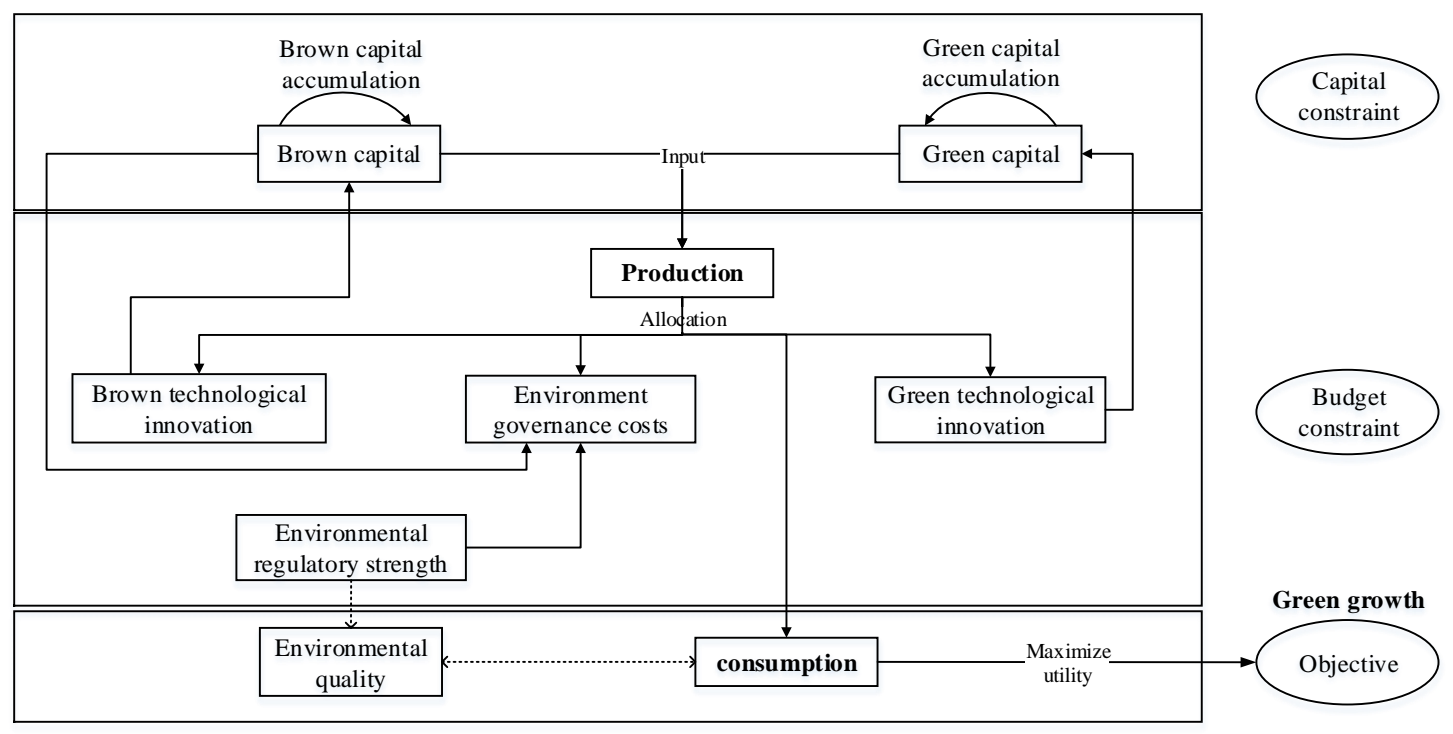

Figure 1. Structure of the theoretical model on the impact of the environmental regulatory strength on directed technological innovation

The second section involves hypothetical conditions concerning the impact of environmental regulatory strength on directed technological innovation, which leads to the creation of a more applicable non-linear optimal control model. The third section seeks an analytical solution to the model in a balanced situation. The fourth section uses parameter values to perform a value simulation of the model created and the analytical solution sought. Finally, we derives a research conclusion.

\section{Materials and methods}

\section{Objective function}

Regarding the utility function $U(C(t), E(t))$ of the green objective, the Cobb-Douglas function format is used, and consumption $C(t)$ and environmental quality $E(t)$ are used as the independent variables of the utility function. For the random variables $x(t)$ and $\dot{x}(t)=d x / d t$, the expression can be simplified by omitting the time variable $t$ as follows:

$$
U(C, E)=\left\{\begin{array}{lr}
\frac{\left(C E^{\eta}\right)^{1-\theta}}{1-\theta}, & \theta \neq 1,0 \leq \eta<1, \\
\ln C+\eta \ln E, & \theta=1,0 \leq \eta<1 .
\end{array}\right.
$$

In Eq.1, the objective of maximizing social welfare concerns the maximizing of the total discounted value of the instantaneous utility of consumers, i.e. $\max \int_{0}^{\infty} U(C, E) e^{-\rho t} d t$, 
where the $\rho$ variable is the discount rate of the consumers' subjective time, $\theta>0$ is the relative risk aversion coefficient, and the weighted parameter $\eta>0$ is the environmental quality utility index.

\section{Constraints}

(1) Assuming the effects of economies of scale remain unchanged, all production uses a standardized technology to produce similar products. The Cobb-Douglas function format is adopted for the production of the product, with the production factors being differentiated into brown capital and green capital, which can be displayed as $Y=b K^{\alpha} G^{l-\alpha}$, where $b$ is the size parameter for the production function, $K$ is the brown capital stock, $G$ is the green capital stock, and $\alpha \in(0,1)$ is the production flexibility of brown capital during the production process (also referred to as productive capital flexibility).

(2) Assuming the effects of economies of scale remain unchanged, we adopt the Cobb-Douglas function format for capital accumulation. The production factors are mainly composed of the capital stock and different technological innovation investment inputs, which means that the brown capital and green capital accumulation process has the form,

$$
\begin{aligned}
& \dot{K}=d K^{\delta} R_{K}^{1-\delta}-\phi K \\
& \dot{G}=e G^{\sigma} R_{G}^{1-\sigma}-\psi G
\end{aligned}
$$

In Eq.2 and Eq.3, $R_{K}$ is the brown technological innovation investment and $R_{G}$ is the green technological innovation investment. $d$ is the brown capital accumulation size parameter, $e$ is the green capital accumulation size parameter, $\delta, \sigma \in(0,1)$ are production flexibilities during the accumulation of brown capital and green capital, $\Phi$ is the depreciation ratio of brown capital, and $\Psi$ is the depreciation ratio of green capital. Assuming that the positive impact of capital stock inputs on capital accumulation is smaller than the technological innovation investment inputs, the production flexibility of capital stock amid capital accumulation should be smaller than the technological innovation investments. In other words, $\delta, \sigma \in(0,0.5)$. In addition, compared to green capital, capital accumulation (Bondarev et al., 2014) is easier for brown capital. In that case, the production flexibility of green capital amid capital accumulation should not be larger than brown capital. In other words, $\sigma \leq \delta$.

(3) Assuming there is perfect competition in the market, for the products produced that can be used for consumption, brown technological innovation investments, green technological innovation investments, and environmental pollution governance, the budget constraints can be expressed as follows: $Y(K, G)-C-w\left(R_{K}+R_{G}\right)-X(E) K=0$. Here, $w$ refers to the inorganic opportunity costs of technological innovation investments, $X(E)$ refers to the environmental regulatory strength, and $X(E) K$ refers to the environment governance costs. Among these, there is a positive relationship between environmental regulatory strengths $X(E)$ and environmental quality $E$. Assuming $X(E)$ concerns the monotonically increasing function of $E$, it can be displayed as $X(E)=a E^{\beta}$, where $a>0$ is referred to as the fixed proportional coefficient for eliminating costs and $\beta>1$ is the index for eliminating costs. 


\section{Non-linear optimal control model}

To summarize the above, the utility function $U(C, E)$ adopting a logarithmic form is a strongly convex function, satisfying the conditions for establishing an optimal control model. Taking into account the changes in the brown capital stock $K$, green capital stock $G$, brown technological innovation investment $R_{K}$, green technological innovation investment $R_{G}$ and environmental governance costs $X(E) K$, we give the following nonlinear optimal control model,

$$
\max _{C, E} W=\max _{C, E} \int_{0}^{\infty} U(C, E) \cdot e^{-\rho t} d t
$$

s.t. Eq.1 Eq.3.

$$
\begin{gathered}
Y=b K^{\alpha} G^{1-\alpha} \\
b K^{\alpha} G^{1-\alpha}-C-w\left(R_{K}+R_{G}\right)-a E^{\beta} \cdot K=0 \\
K(0)=K_{0}>0, G(0)=G_{0}>0
\end{gathered}
$$

where $R_{K}$ and $R_{G}$ are the control variables and $K, G$, and $C$ are the state variables.

To find the optimal solution, taking $\lambda_{K}$ and $\lambda_{G}$ to be the common-mode variables of brown capital stock $K$ and green capital stock $G$ (shadow prices with different capital stock), the Hamiltonian in Eq.8 is formed as follow,

$$
H(\cdot)=\frac{\left(C E^{\eta}\right)^{1-\theta}}{1-\theta}+\lambda_{K}\left(d K^{\delta} R_{K}^{1-\delta}-\phi K\right)+\lambda_{G}\left[e G^{\sigma} R_{G}^{1-\sigma}-\psi G\right]
$$

We apply standard Pontryagin maximum principle to find a control optimal in problem of Eq.1 Eq.7, the maximization conditions should satisfy

$$
\begin{gathered}
\frac{\partial H}{\partial R_{K}}=0 \\
\frac{\partial H}{\partial R_{G}}=0
\end{gathered}
$$

This maximization leads to the Euler equation,

$$
\begin{aligned}
& \dot{\lambda}_{K}=-\frac{\partial H}{\partial K}+\rho \lambda_{K} \\
& \dot{\lambda}_{G}=-\frac{\partial H}{\partial G}+\rho \lambda_{G}
\end{aligned}
$$


Under the requirement that the following set of transversality conditions,

$$
\begin{aligned}
& \lim _{t \rightarrow \infty} e^{-\rho t} \lambda_{K} K=0 \\
& \lim _{t \rightarrow \infty} e^{-\rho t} \lambda_{G} G=0
\end{aligned}
$$

From Eq.9 Eq.12, it then follows that the costate variable associated to brown capital stock $K$ and green capital stock $G$,

$$
\begin{aligned}
& \lambda_{K}=\frac{w C^{-\theta} E^{\eta(1-\theta)}}{d(1-\delta) K^{\delta} R_{K}^{-\delta}}>0 \\
& \lambda_{G}=\frac{w C^{-\theta} E^{\eta(1-\theta)}}{e(1-\sigma) G^{\sigma} R_{G}^{-\sigma}}>0
\end{aligned}
$$

In Eq.15 Eq. 16, both $\lambda_{K}$ and $\lambda_{G}$ are positive values. Therefore, the Hession matrix of the Hamiltonian is as follows,

$$
\begin{aligned}
& \mathrm{H}=\left(\begin{array}{cc}
\frac{\partial^{2} H}{\partial R_{K}^{2}} & \frac{\partial^{2} H}{\partial R_{K} \partial R_{G}} \\
\frac{\partial^{2} H}{\partial R_{K} \partial R_{G}} & \frac{\partial^{2} H}{\partial R_{G}^{2}}
\end{array}\right) \\
& =\left(\begin{array}{cc}
-w^{2} \theta C^{-\theta-1} E^{\eta(1-\theta)}-\lambda_{K} d \delta(1-\delta) K^{\delta} R_{K}^{-\delta-1} & -w^{2} \theta C^{-\theta-1} E^{\eta(1-\theta)} \\
-w^{2} \theta C^{-\theta-1} E^{\eta(1-\theta)} & -w^{2} \theta C^{-\theta-1} E^{\eta(1-\theta)}-\lambda_{G} e \sigma(1-\sigma) G^{\sigma} R_{G}^{-\sigma-1}
\end{array}\right)
\end{aligned}
$$

The Eq.17 is negative definite, which means that current-value of the Hamiltonian is a strongly convex function which has a maximum value.

\section{Results}

From $E q .6$, we can obtain consumption $C$, which is the function of variables $K, G, R_{K}$, and $R_{G}$, which is as follows:

$$
C\left(K, G, R_{K}, R_{G}\right)=b K^{\alpha} G^{1-\alpha}-w\left(R_{K}+R_{G}\right)-a E^{\beta} K
$$

The problem of Eq.1 Eq.7 can be simplified to a problem with only four variables, i.e., $K, G, R_{K}$, and $R_{G}$, where $E q .8$ is the objective function, Eq.2, Eq.3, Eq.9 Eq.14 and Eq. 18 are the constraints, $R_{K}$ and $R_{G}$ are the control variables, and $K$ and $G$ are the state variables.

From Eq.9, we can obtain the equation

$$
\frac{\dot{\lambda}_{K}}{\lambda_{K}}=-\theta \frac{\dot{C}}{C}-\delta \frac{\dot{K}}{K}+\delta \frac{\dot{R}_{K}}{R_{K}}
$$


combining Eq.11, we can obtain the equation

$$
\frac{\dot{\lambda}_{K}}{\lambda_{K}}=\rho+\phi-d \delta\left(\frac{R_{K}}{K}\right)^{1-\delta}-\frac{d(1-\delta)}{w}\left(\frac{R_{K}}{K}\right)^{-\delta}\left[\alpha b\left(\frac{G}{K}\right)^{1-\alpha}-a E^{\beta}\right]
$$

Similarly, from Eq.10, we can obtain the equation

$$
\frac{\dot{\lambda}_{G}}{\lambda_{G}}=-\theta \frac{\dot{C}}{C}-\sigma \frac{\dot{G}}{G}+\sigma \frac{\dot{R}_{G}}{R_{G}}
$$

combining Eq.12, we can obtain the equation

$$
\frac{\dot{\lambda}_{G}}{\lambda_{G}}=\rho+\psi-e \sigma\left(\frac{R_{G}}{G}\right)^{1-\sigma}-\frac{e(1-\sigma)}{w}\left(\frac{R_{G}}{G}\right)^{-\delta}(1-\alpha) b\left(\frac{G}{K}\right)^{-\alpha}
$$

To achieve green growth, we set $K$ and $G$ to be constants, which means $\dot{R}=\dot{G}=0$. Combining Eq.2 and Eq.3, we can obtain the equations

$$
\begin{aligned}
& \frac{R_{K}}{K}=\left(\frac{\phi}{d}\right)^{1 /(1-\delta)} \\
& \frac{R_{G}}{G}=\left(\frac{\psi}{e}\right)^{1 /(1-\sigma)}
\end{aligned}
$$

Combining Eq.19 Eq.24, the optimal capital allocation $G / K$, and the optimal growth rate of investment for different technological innovations $\dot{R} / R$, and the optimal consumption growth rate $\dot{C} / C$ can be obtained as Eq.25 Eq.28

$$
\begin{gathered}
\frac{G}{K}=\frac{e(1-\alpha)(1-\sigma)}{\alpha d(1-\delta)}\left(\frac{\psi}{e}\right)^{\sigma /(\sigma-1)}\left(\frac{d}{\phi}\right)^{\delta /(\delta-1)} \frac{\rho+\phi+\theta g-\delta \phi+\frac{a d(1-\delta)}{w}\left(\frac{\phi}{d}\right)^{\delta /(\delta-1)} E^{\beta}}{\rho+\psi+\theta g-\sigma \psi} \\
\frac{\dot{R}_{K}}{R_{K}}=\frac{\rho+\phi+\theta g_{C}}{\delta}-\phi-\frac{d(1-\delta)}{w \delta}\left(\frac{\phi}{d}\right)^{\delta /(\delta-1)}\left[\alpha b\left(\frac{G}{K}\right)^{1-\alpha}-a E^{\beta}\right] \\
\frac{\dot{R}_{G}}{R_{G}}=\frac{\rho+\psi+\theta g_{C}}{\sigma}-\psi-\frac{e(1-\sigma)}{w \sigma}\left(\frac{\psi}{e}\right)^{\sigma /(\sigma-1)}(1-\alpha) b\left(\frac{G}{K}\right)^{-\alpha} \\
\frac{\dot{C}}{C}=\rho+\psi-\sigma \psi-\frac{e(1-\sigma)}{w}\left(\frac{\psi}{e}\right)^{-\frac{\delta}{1-\delta}}(1-\alpha) b\left(\frac{G}{K}\right)^{*}
\end{gathered}
$$




\section{Discussion}

\section{Data source}

The empirical value of different parameters in nonlinear optimal control model of existing research is shown as Table 1 .

Refer to Figure 1 for the "experience points" of different parameters for the models being researched. We perform a data simulation of the relationship between environmental regulatory strength $E$, capital allocation $G / K$, and the growth rate of investment for different technological innovations $\dot{R} / R$.

Table 1. Key parameter values

\begin{tabular}{c|c|c|c}
\hline Parameter & Value & Definition & Reference Source \\
\hline$a$ & 1 & Fixed Proportional Coefficient for eliminating costs & Rauscher, 2009 \\
$\alpha$ & 0.6 & Productive Capital Flexibility & Roseta-Palma et al., 2010 \\
$b$ & 1 & Size Parameter of Production Function & Antoci et al., 2012 \\
$d$ & 1 & Size Parameter of Brown Capital Accumulation & Antoci et al., 2012 \\
$e$ & 1 & Size Parameter of Green Capital Accumulation & Feenstra et al., 2001 \\
$\rho$ & 0.05 & Chu and Lai, 2013 \\
$\theta$ & $2-2.5$ & Relative Risk Aversion Coefficient & Antoci et al., 2012 \\
$w$ & 0.1 & Inorganic Opportunity Costs Of Technological Innovation & Antoci et al., 2012 \\
$\beta$ & 2 & Investments & Antoci et al., 2012 \\
$\eta$ & 0.4 & Index for Eliminating Costs & Antoci et al., 2012 \\
$\delta$ & 0.4 & Production Flexibility Where Brown Capital Is Being & Feenstra et al., 2001 \\
$\sigma$ & 0.3 & Accumulated & Rauscher, 2009 \\
$\varphi$ & 0.01 & Production Flexibility Where Green Capital Is Being & Accumulated \\
$\psi$ & 0.01 & Brown Capital Depreciation Rate & Bilancini and D'Alessandro, \\
$a$ & 1 & Freen Capital Depreciation Rate & Bovenberg and Smulders, \\
& & Fixed Proportional Coefficient For Eliminating Costs & Rauscher, 2009 \\
\hline
\end{tabular}

\section{Analysis of the impact of environmental quality $E$ on capital allocation $G / K$}

We perform a data simulation of the impact of different environmental quality $E$ on the capital allocation $G / K$, with the balanced growth rate as $g=0.0235$, the discount rate as $\rho=0.05$, productive capital flexibility as $\alpha=0.6$, and the inorganic opportunity costs of technological innovation investment as $w=0.1$, and the other parameters are fixed. Figure 2 indicates that the capital allocation $G / K$ concerns the strongly monotonically increasing concave function of the environmental regulatory strength $E$. With an increase in $E$, the environmental quality, the green capital ratio $G /(K+G)$ increases and accelerates faster. When $E=0$, which represents the absence of environmental regulations, brown capital can be accumulated (Bondarev et al., 2014) relatively easily compared to green capital, which will cause brown capital to be used as much as possible during production. However, using brown capital can further pollute the environment. In addition, environmental regulations strength $X(E)$ and environmental quality $E$ are positively correlated, which thus results in an increase in expenditure on environmental governance costs $X(E) K$. Once the environmental quality $E$ increases, the green capital ratio $G /(K+G)$ presents a growth trend because the use of green capital can replace brown capital to reduce environmental pollution. At this point, brown capital is no longer considered to be critical capital for production, which causes capital 
allocation to switch towards green technological innovation. In addition, this trend becomes more significant as environmental quality $E$ increases to $E=1$, which refers to stricter environmental regulations.

To more clearly explain the impact of environmental quality $E$ on capital allocation $G / K$, we perform a data simulation of the impact of different environmental qualities $E$ on the capital allocation $G / K$, with the balanced growth rate as $g=\{0,0.0135,0.0235$, $0.0535\}$ and the other parameters being fixed. Figure 2 shows that the balanced growth rate $g$ and capital allocation $G / K$ are negatively correlated. However, this finding does not change the impact of environmental quality $E$ on capital allocation $G / K$. When the environmental quality is $E=0.7$, the different balanced growth rates $g$ corresponding to capital allocation ratio $G / K$ are $P_{0}, P_{0.0135}, P_{0.0235}$, and $P_{0.0535}$, with $P_{0}>P_{0.0135}>P_{0.0235}>$ $P_{0.0535}$, respectively. The implication is that in the same environmental quality $E$, when the balanced growth rate $g$ is higher, the green capital ratio $G /(K+G)$ is lower, which illustrates the production flexibility of brown capital in capital accumulation. This finding signifies the easing of the fall of capital accumulation, in which brown capital is being used as much as possible.

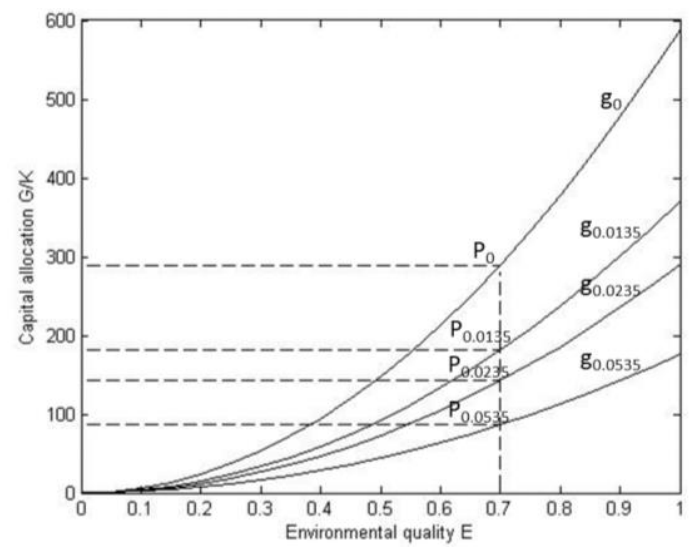

Figure 2. Impact of balanced growth rate $g$ on capital allocation $G / K$

Furthermore, we perform a data simulation of the impact of different environmental qualities $E$ on the capital allocation $G / K$ where the discount rate is $\rho=\{0.001,0.01,0.015$, $0.05\}$, production capital flexibility is $\alpha=\{0.8,0.7,0.6,0.5\}$, the inorganic opportunity costs of technological innovation investment are $w=\{0.05,0.1,0.15,0.2\}$, and the other parameters are fixed. Figure 3 and Figure 4 show that the green capital ratio $G /(K+G)$ will exhibit a growing trend when the same environmental quality $E$ declines, the discount rate $\rho$ declines, or production capital flexibility $\alpha$ declines. The implication is that when brown capital is producing, which negatively affects consumption and environmental pollution governance, the utilization of brown capital will be reduced. This reduction will stagnate the economic growth of society as a whole. Given this situation, it is possible to simulate a recovery in economic growth by simply raising green capital utilization efforts, which proves that green capital is an important pillar for maintaining the economic growth of society as a whole. On the other hand, there is a negative correlation between the inorganic opportunity costs of technological innovation investment $w$ and the green capital ratio $G /(K+G)$. For details, refer to Figure 5. Assuming that environmental quality $E$ does not change, the increase in the inorganic opportunity costs of technological innovation investment $w$ means that similar 
subsidies are given whether the technological innovation is green or brown. The implication is that provided that the requirements under environmental qualities $E$ are satisfied, priority is given to the utilization of brown capital. Thus, brown capital shall enjoy greater production flexibility in capital accumulation.

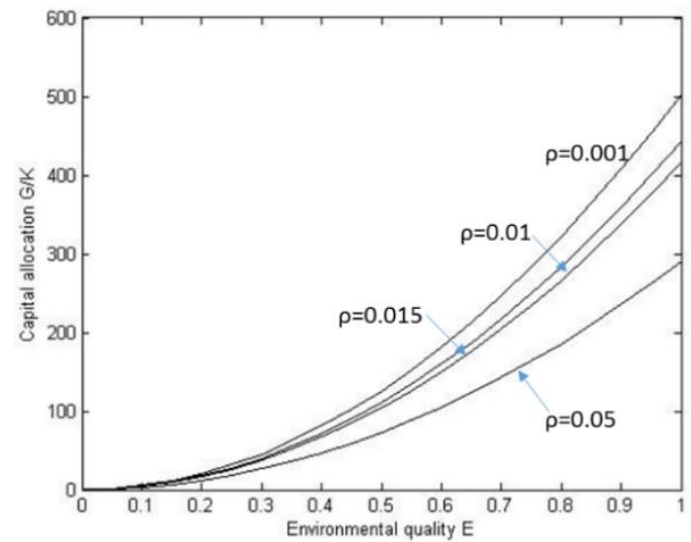

Figure 3. Impact of discount rate $\rho$ on capital allocation $G / K$

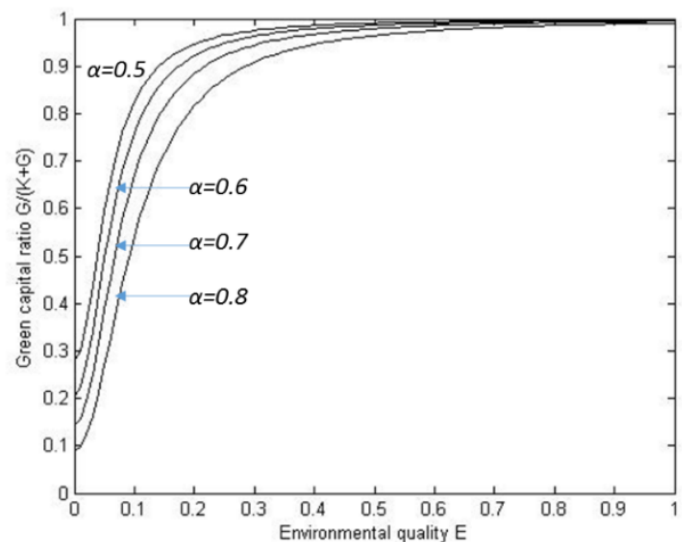

Figure 4. Impact of production capital flexibility $\alpha$ on capital allocation $G / K$

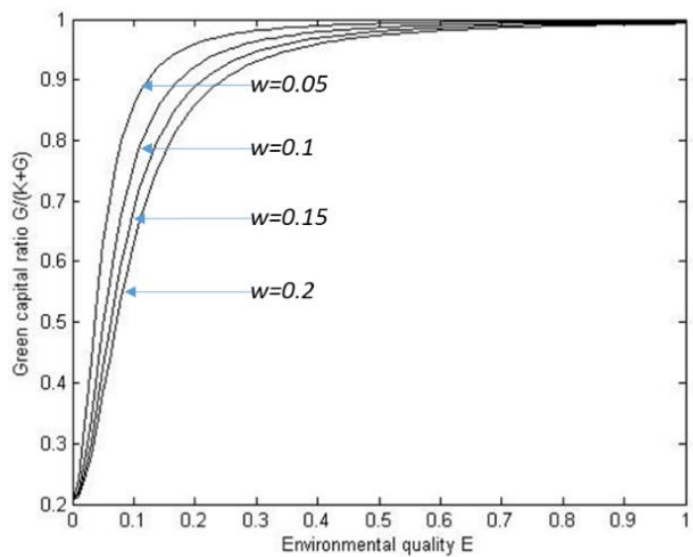

Figure 5. Impact of technological innovation investment inorganic opportunity costs $w$ on capital allocation $G / K$ 


\section{Impact of capital allocation $G / K$ on the optimal consumption growth rate $\dot{C} / C$}

Incorporating Eq.25 in Eq.26 and Eq.27, the growth rate of investment for different technological innovations $\dot{R} / R$ reconstructs the partial derivatives of capital allocation $G / K$

$$
\begin{aligned}
& \frac{\partial \dot{R}_{K} / R_{K}}{\partial G / K}=-\frac{\alpha b d(1-\delta)(1-\alpha)}{w \delta}\left(\frac{g_{K}+\phi}{d}\right)^{\delta /(\delta-1)}\left(\frac{G}{K}\right)^{-\alpha}<0 \\
& \frac{\partial \dot{R}_{G} / R_{G}}{\partial G / K}=\frac{\alpha b e(1-\alpha)(1-\sigma)}{w \sigma}\left(\frac{g_{G}+\psi}{e}\right)^{\sigma /(\sigma-1)}\left(\frac{G}{K}\right)^{-1-\alpha}>0
\end{aligned}
$$

From Eq.29 and Eq.30, it is observed that the obtainable investment ratio of brown technological innovation $\dot{R}_{K} / R_{K}$ is related to the monotonous decreasing function of capital allocation $G / K$. In addition, the investment rate of green technological innovation $\dot{R}_{G} / R_{G}$ is related to the monotonous increasing function of capital allocation $G / K$. We perform a data simulation of the impact of different capital allocation $G / K$ on the investment rate of technological innovation $\dot{R} / R$ with $g=0.0135$ and the other parameters being fixed. Figure 6 shows that the investment rate of both brown technological innovation $\dot{R}_{K} / R_{K}$ and the investment rate of green technological innovation $\dot{R}_{G} / R_{G}$ converge to a certain fixed value; however, the convergence value of the investment rate of green technological innovation $\dot{R}_{G} / R_{G}$ is higher than the investment rate of brown technological innovation $\dot{R}_{K} / R_{K}$. Once, which means that the investments rates of technological innovation have reached equilibrium, the capital allocation $(G / K)^{*}$ reaches the optimal balanced capital allocation ratio $(G / K)^{*}=0.5$. The implication is that green technological innovation investments relative to brown technological innovation investments can bring about a greater value of economic growth.

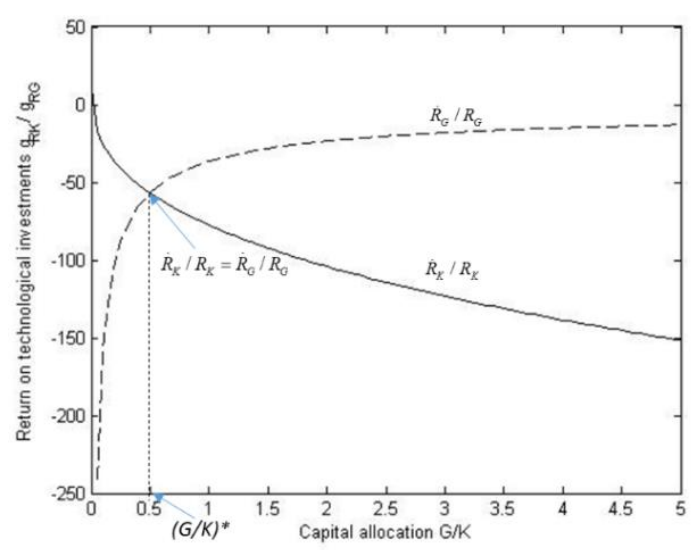

Figure 6. Impact of capital allocation $G / K$ on the rate of technological investments $\dot{R} / R$

To further clarify the impact of capital allocation $G / K$ on the optimal consumption growth rate $\dot{C} / C$, we perform a simulation on the impact of different capital allocation $G / K$ on the optimal consumption growth rate $\dot{C} / C$, where the capital allocation ratio is $G / K=\{0.2,0.5,1\}$ and the other parameters are fixed. Figure 7 shows that for different 
capital allocation ratios $G / K$, the trajectory of the optimal consumption growth rate is different. Only when $G / K=0.5$ is the optimal consumption growth rate the highest. In addition, with an increase in environmental regulations, there is a monotonic increase in the optimal consumption growth rate. Regarding two other situations in which $G / K<0.5$ and $G / K>0.5$, the optimal consumption growth rate must be lower than $G / K=0.5$. Simultaneously, from the analysis in Figure 6 , we know that $G / K=0.5$ is also the equilibrium point of the investment rate of technological innovation.

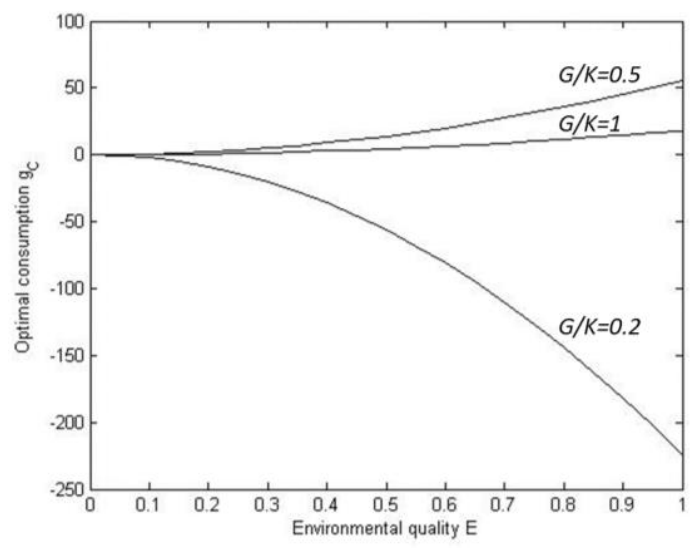

Figure 7. Impact of capital allocation $G / K$ on optimal consumption growth rate $\dot{C} / C$

Because it is not necessary to consider a negative impact on the environment due to the lower research and development costs of brown technological innovation, the products that were put into production will have greater profits and market potential. Therefore, brown capital stock will increase by a greater extent along with capital accumulation. However, this increase may easily spark a new vicious cycle of economic growth that over-relies on brown technological innovation. By analyzing the optimal consumption growth rate, we can determine that it is mainly driven by brown capital and that the impact of green capital on the optimal consumption growth rate must be lower than that of brown capital. In addition, other than consumption per se, environmental improvements would benefit the social welfare that people eventually seek. Therefore, from another perspective, as environmental regulations increase, even if green capital does not result in a rapid growth in consumption, improvements in the environment will compensate for this shortcoming, which not only proves that the implementation of environmental regulations can help increase the drivers of green technological innovation but also further proves that green technological innovation can boost the economic growth of society as a whole. The reason is the social value that it brings is much greater. In particular, it can also effectively ease the negative impact on the environment.

\section{Conclusion}

From the perspective of green growth theory, the present research takes into account the impact of the implementation of environmental regulations on directed technological innovations and incorporates the following into the framework for the analysis of capital accumulation: 
(1) Brown technological innovation that involves environmental regulations and environmental governance costs;

(2) Green technological innovations that can effectively protect the environment.

Assuming the effect of the economies of scale remains unchanged and that there is perfect competition in the market, we draw reference from the method of quantitative expression of green growth targets by Moser et al. (2013) and the method of brown technological innovation investment and green technological innovation investments by Rauscher (2009). In doing so, we construct a non-linear optimal control model in which the relative risk aversion coefficient $>0$, the green growth target of maximizing social welfare is the objective function, and the constraint is the ensuring of the constant growth of the balanced growth rate and the constant improvement in environmental quality. Using optimal control theory and the maximum principle, we separately obtain the quantitative expression for the investment rate of brown technological innovation $\dot{R}_{K} / R_{K}$, the investment rate of green technological innovation $\dot{R}_{G} / R_{G}$, and capital allocation $G / K$. Finally, we perform a data simulation of the problem regarding the impact of environmental regulatory strength on the selection of directed technological innovation to drive the economic growth of society as a whole. The simulation results are as follows:

(1) Environmental regulatory strength $E$ has a positive impact on the green capital ratio $G /(K+G)$, which means that the implementation of environmental regulations can subdue the increase in environmental pollution and achieve the shift of capital allocation towards green technological innovation fields.

(2) The balanced growth rate $g$, the discount ratio $\rho$, productive capital flexibility $\alpha$, and the inorganic opportunity costs of technological innovation investment $w$ have a negative impact on the green capital ratio $G /(K+G)$, which proves that brown capital has superior production flexibility in capital accumulation. Although this finding means that brown capital can ease the fall in capital accumulation, it also proves that green capital is necessary for the economic growth of society as a whole.

(3) The green capital ratio $G /(K+G)$ has a negative impact on the investment rate of brown technological innovation $\dot{R}_{K} / R_{K}$ and a positive impact on the investment rate of green technological innovation $\dot{R}_{G} / R_{G}$. However, green technological innovation, relative to brown technological innovation, can create a greater value of economic growth.

(4) The environmental quality $E$ has a positive impact on the investment rate of technological innovation $\dot{R}_{K} / R_{K}=\dot{R}_{G} / R_{G}$ and the corresponding green capital ratio $G /(K+G)$ when in a balanced state. This result not only reconfirms that the stronger the implementation of environmental regulations is, the more it benefits the utilization of green capital, but it also further affirms that the implementation of environmental regulations will direct capital allocation towards the new field of green technological innovations. The reason is the utilization of green technological innovations shall play a more effective role than brown technological innovations in achieving green growth (a rise in economic growth and improvement in environmental quality).

The above-mentioned simulation results can provide government decision makers with proven management guidance in formulating suitable environmental regulations with the aim of directing capital allocation towards green technological innovation fields and further achieving green growth. However, the present research also takes into account relatively ideal external factors such as the effects of economies of scale remaining unchanged, the operating status of the market economy, the relationship 
between pollution governance efforts and environmental regulatory strength, the capital allocation, and production technological conditions under different types of capital. Therefore, our next research direction will involve taking into account more realistic factors or problems with green growth after adequately broadening the scope of the above-mentioned assumptions.

Acknowledgements. We are grateful for financial support to the first author from the International Cooperation and Exchanges NSFC of China (71320107006) and Program for Innovative Research Team in University of Ministry of Education of China (IRT_17R13); and to the second and corresponding author from the NSFC of China (71831002, 71403035), Foundation for Humanities and Social Sciences of Ministry of Education of China (18YJC630261) and Key R\&D Program for Soft Science Project of Liaoning Province of China (2018401030).

\section{REFERENCES}

[1] Antoci, A., Russu, P., Ticci, E. (2012): Environmental externalities and immiserizing structural changes in an economy with heterogeneous agents. - Ecological Economics 81(3): 80-91.

[2] Arduini, R., Cesaroni, F. (2002): Environmental technologies in the European chemical industry. - Lem working papers series, Sant'Anna School of Advanced Studies, Pisa, Italy.

[3] Barbera, A. J., Mcconnell, V. D. (1990): The impact of environmental regulations on industry productivity: direct and indirect effects. - Journal of Environmental Economics \& Management 18(1): 50-65.

[4] Bilancini, E., D'Alessandro, S. (2011): Long-run welfare under externalities in consumption, leisure, and production: a case for happy degrowth vs. Unhappy growth. Ecological Economics 84(6): 194-205.

[5] Bondarev, A., Clemens, C., Greiner, A. (2014): Climate change and technical progress: impact of informational constraints. - In: Dynamic Optimization in Environmental Economics. Dynamic Modeling and Econometrics in Economics and Finance 15. Berlin, Heidelberg: Springer.

[6] Bovenberg, A. L., Smulders, S. A. (1996): Transitional impacts of environmental policy in an endogenous growth model. - International Economic Review 37(4): 861-893.

[7] Caselli, F. (2005): Accounting for cross-country income differences. - Lse Research Online Documents on Economics 1(5): 679-741.

[8] Chu, H., Lai, C. C. (2013): Abatement R\&D, market imperfections, and environmental policy in an endogenous growth model. - Journal of Economic Dynamics \& Control 41(1): 20-37.

[9] Demirel, P., Kesidou, E. (2011): Stimulating different types of eco-innovation in the UK: government policies and firm motivations. - Ecological Economics 70(8): 1546-1557.

[10] Feenstra, T., Kort, P. M., Zeeuw, A. D. (2001): Environmental policy instruments in an international duopoly with feedback investment strategies. - Journal of Economic Dynamics \& Control 25(10): 1665-1687.

[11] Gans, J. S. (2009): Innovation and climate change policy. - American Economic Journal Economic Policy 4(4): 125-145.

[12] Gerlagh, R. (2011): Too much oil. - CESifo Economic Studies 57(1): 79-102.

[13] Ghisetti, C., Pontoni, F. (2015): Investigating policy and R\&D effects on environmental innovation: a meta-analysis. - Ecological Economics 118(5): 57-66.

[14] Goulder, L. H. (2004): Induced technological change and climate policy. - Pew Center on Global Climate Change, Arlington, VA. 
[15] Hamamoto, M. (2006): Environmental regulation and the productivity of japanese manufacturing industries. - Resource \& Energy Economics 28(4): 299-312.

[16] Hart, R. (2004): Growth, environment and innovation - a model with production vintages and environmentally oriented research. - Journal of Environmental Economics \& Management 48(3): 1078-1098.

[17] Jaffe, A. B., Newell, R. G., Stavins, R. N. (2002): Technological change and the environment. - Social Science Electronic Publishing 1(3): 461-516.

[18] Johnstone, N., Hascic, I., Poirier, J., Hemar, M., Michel, C. (2012): Environmental policy stringency and technological innovation: evidence from survey data and patent counts. Applied Economics 44(17): 2157-2170.

[19] Li, L., Tao, F. (2012): Selection of the optimal environmental regulatory strength in China's manufacturing sector: A perspective based on green total factor productivity. Industrial Economics of China 5(5): 70-82.

[20] Li, J. W., Guan, Q., Yang, H. (2018): Winter energy consumption in reading space of green library in cold regions. - International Journal of Heat and Technology 36(4): 1256-1261.

[21] Maria, C. D., Werf, E. V. D. (2008): Carbon leakage revisited: unilateral climate policy with directed technical change. - Environmental and Resource Economics 39(2): 55-74.

[22] Moser, E., Prskawetz, A., Tragler, G. (2013): Environmental regulations, abatement and economic growth. - In: Green Growth and Sustainable Development. Dynamic Modeling and Econometrics in Economics and Finance 14. Berlin, Heidelberg: Springer.

[23] Nakano, M. (2003): Can environmental regulation improve technology and efficiency: an empirical analysis using the Malmquist productivity Index. - Eaere 6: 28-30.

[24] OECD. (2011): Towards green growth. - OECD Meeting of the Council (16): 8-37.

[25] Rauscher, M. (2009): Green r\&d versus end-of-pipe emission abatement: a model of directed technical change. - Working paper No. 106, Thuenen-Series of Applied Economic Theory, Institute of Economics, University of Rostock, Rostock.

[26] Roseta-Palma, C., Ferreira-Lopes, A., Sequeira, T. N. (2010): Externalities in an endogenous growth model with social and natural capital. - Ecological Economics 69(3): 603-612.

[27] Rubashkina, Y., Galeotti, M., Verdolini, E. (2015): Environmental regulation and competitiveness: empirical evidence on the porter hypothesis from european manufacturing sectors. - Ssrn Electronic Journal 83(35): 288-300.

[28] Shen, N. (2012): Threshold effect of the impact of environmental regulations on regional technological innovation. - China's population, resources, and environment 22: 12-16.

[29] Smulders, S., Nooij, M. D. (2003): The impact of energy conservation on technology and economic growth. - Resource \& Energy Economics 25(1): 59-79.

[30] Smulders, S., Werf, E. V. D. (2008): Climate policy and the optimal extraction of highand low-carbon fossil fuels. - Canadian Journal of Economics/Revue canadienne d'économique 41(4): 1421-1444.

[31] Stokey, N. L. (1998): Are there limits to growth. - International Economic Review 39(1): $1-31$.

[32] Zhang, C., Lu, Y., Guo, L. (2011): Environmental regulatory strength and advancement in production technology. - Economic research 2: 113-124.

[33] Zhang, J. L., Zhu, L. (2012): Research on industrial enterprise technological innovation effectiveness based on green growth in different parts of China. - Technological economic research in quantitative economics 2: 113-125. 